\title{
Effects of Hydrocortisone, Glycerophosphate and Retinol on the Differentiation of Mesenchymal Stem Cells and Vascular Endothelial Cells to Osteoblasts
}

\author{
Naofumi Shiomi, Keiko Watanabe \\ School of Human Sciences, Kobe College, Nishinomiya, Japan \\ Email: n-shiomi@mail.kobe-c.ac.jp
}

Received 12 September 2014; revised 27 October 2014; accepted 12 November 2014

Copyright (C) 2014 by authors and Scientific Research Publishing Inc.

This work is licensed under the Creative Commons Attribution International License (CC BY).

http://creativecommons.org/licenses/by/4.0/

c) (i) Open Access

\begin{abstract}
Vascular calcification, which causes occlusion and rupture of the vascular, is often observed in patients in the advanced stages of arteriosclerosis. One of the best procedures for inhibiting the accumulation of vascular calcification is to obstruct the differentiation of mesenchymal stem cells (MSCs) and/or vascular endothelial cells (VECs) in the vascular to osteoblasts. In this study, we evaluated the biochemical and genetic characteristics of the process of differentiation of MSCs and VECs to osteoblasts. C3H10T1/2 MSCs, TKD2 VECs and MC3T3-E1 preosteoblasts (POBs) were cultured in medium containing both hydrocortisone and glycerophosphate. These compounds showed strong effects promoting the differentiation of VECs as well as POBs, although the effect was weak in the MSCs. Moreover, C3H10T1/2 MSCs and TKD2 VECs were cultured in medium containing $10 \mathrm{mM}$ retinol, after which the alkali phosphatase (ALP) activity of the MSCs and production of calcified nodules of TKD2 were significantly increased, whereas the marker genes for the osteoblasts were not. These results suggest that retinol does not have an effect in inducing the differentiation of VECs to osteoblasts, but rather exhibits a strong promoting effect on differentiation.
\end{abstract}

\section{Keywords}

Vascular Calcification, Osteoblasts, Vascular Endothelial Cells, Mesenchymal Stem Cells, Retinol, Hydrocortisone

\section{Introduction}

Isomeric heart disease, one of the main causes of death in Japan, is induced by arteriosclerosis, and vascular cal-

How to cite this paper: Shiomi, N. and Watanabe, K. (2014) Effects of Hydrocortisone, Glycerophosphate and Retinol on the Differentiation of Mesenchymal Stem Cells and Vascular Endothelial Cells to Osteoblasts. J. Biomedical Science and Engineering, 7, 1056-1066. http://dx.doi.org/10.4236/jbise.2014.713103 
cification is often observed in such patients. Vascular calcification enhances the risk of death, as it makes the blood vessels fragile and causes the occlusion and rupture [1]. In particular, an extremely dangerous state is introduced by vascular calcification in patients with chronic renal failure [2] [3] and type 2 diabetes [4] [5]. Therefore, inhibiting vascular calcification is most important for preventing these serious diseases. However, there are currently no effective inhibitors of vascular calcification, although many drugs and foods to prevent arteriosclerosis have been studied for long periods [6] [7].

Recently, various causes of vascular calcification have been identified [8]-[10]. One such cause is the fragmentation of elastin [11]-[13]. Elastin is fragmented by inflammation and/or stress at sites of plaque in patients with arteriosclerosis. These fragments attract many calcium molecules, resulting in calcium deposition. Another cause of vascular calcification is the appearance of osteoblasts at sites of plaque. Previous researchers have reported that cartilage- or osteoblast-like tissue is observed in ApoE and Matrix Gla Protein knockout mice [14] as well as patients exhibiting arteriosclerosis [15]. As osteoblasts and cartilage are not present in normal blood vessels, these results suggest that MSCs (mesenchymal stem cells) and/or VECs (vascular endothelial cells) show vascular differentiation to osteoblasts. In addition, various researchers have studied the mechanisms and compounds promoting the differentiation of POBs, providing important information. For example, some proteins, ascorbic acid, hydrocortisone and dexamethasone [16]-[21] have been shown to stimulate the differentiation to osteoblasts. However, the mechanisms and compounds promoting the differentiation of MSCs and VECs have not been thoroughly investigated.

We therefore attempted to clarify the characteristics of the process of differentiation of MSCs and VECs. We selected hydrocortisone, $\beta$-glycerophosphate and retinol as promoting compounds and examined the effects of these agents on differentiation. Consequently, the results suggested that hydrocortisone and $\beta$-glycerophosphate strongly promote the differentiation of VECs to osteoblasts and that the induced cells produce a significant amount of calcified nodules. Moreover, retinol strongly aids the progression of osteoblast maturation.

\section{Materials and Methods}

\subsection{Cell Lines, Media and Additives}

Three murine cell lines, C3H10T1/2 MSC [22], MC3T3-E1 POB [23] and TKD2 VEC [24], were respectively obtained from ECACC CELL LINE (DS PHARMA BIOCHMICAL), Riken Bio Resource Center and JCRB Cell Bank. The cells were cultured in the following three media: 1) basic medium (DMEM), a mixture of Dulbecco's modified Eagle's medium and FBS at a ratio of 9:1, 2) osteoblast-inducing medium (OIM), DMEM containing $1 \%$ hydrocortisone and $1 \% \beta$-glycerophosphate solutions supplied in Osteoblast Inducer Reagent (Takara Co. Ltd., Shiga, Japan), and 3) bone construction medium (BCM), a commercial medium (Code No. OGCMO) obtained from Cosmo Bio Co. Ltd. (Tokyo, Japan). Ascorbic acid or retinol was added to the OIM at a final concentration of $10 \mu \mathrm{M}$ in order to examine their effects. To prepare the solutions, ascorbic acid and retinol were each dissolved in water and ethanol at a final concentration of $10 \mathrm{mM}$ and filtered using a $0.2-\mu \mathrm{m}$ sterilized filter. The culture was performed in a $\mathrm{CO}_{2}$ incubator at $37^{\circ} \mathrm{C}$.

\subsection{Culture Conditions}

The culture conditions for differentiation were as follows. MC3T3-E1, C3H10T1/2 and TKD2 cells $\left(2 \times 10^{4}\right.$ cells) were respectively cultured in 25- $\mathrm{cm}^{2}$ flasks containing $8 \mathrm{~mL}$ of DMEM, OIM and OIM consisting of 10 $\mu \mathrm{M}$ of ascorbic acid or OIM consisting of $10 \mu \mathrm{M}$ retinol for five days, and the obtained cells $\left(2 \times 10^{4}\right.$ cells $)$ from the MC3T3-E1 and TKD2 populations were subcultured for another five days (a total of 10 days of culture). For the C3H10T1/2 cells, the subculture was performed twice (a total of 15 days of culture).

The culture conditions for the analysis were as follows. Each type of cells $\left(5 \times 10^{3}\right.$ and $5 \times 10^{4}$ cells $)$ obtained from the culture for differentiation were cultured in two 24 -well culture plates and two $25-\mathrm{cm}^{2}$ flasks containing medium similar to that used for differentiation for three days. The cells cultured in 24-well plates were used for staining of the ALP activity and an analysis of the proportion of each cell type, and the cells cultured in two $25-\mathrm{cm}^{2}$ flasks were used to detect the ALP activity and gene expression, respectively. The cells $\left(1 \times 10^{4}\right.$ cells $)$ obtained from the culture for differentiation were also cultured in 24-well culture plates containing $2 \mathrm{~mL}$ of BCM for 10 days by exchanging the medium every five days, and the wells were used to detect calcified nodules. A total of three or four independent experiments were performed, and the average values, SD and p-val- 
ues were calculated.

\subsection{ALP Activity and Calcified Nodules}

Staining of the ALP activity was performed using a TRACP\&ALP double-stain kit. Cells cultured in 24-well culture plates were washed twice with PBS, fixed with Fixation solution (45\% acetone, 55\% citrate buffer (pH 4.5) containing $10 \%$ methanol) for five minutes and washed twice with distilled water. The substrate for ALP was added and the mixture was incubated for two hours at $37^{\circ} \mathrm{C}$. The cells were washed three times with $700 \mu \mathrm{L}$ of distilled water and observed under a microscope. Cells cultured in other 24-well culture plates were also stained according to a similar method, with the exception of the reaction time with the substrate for ALP, which was prolonged from two to 12 hours. The number of stained cells in total was calculated using four pictures obtained in randomly selected positions.

The activity of ALP was determined using the Labo Assay TMAP kit (Wako Chemical Co., Tokyo, Japan). Cells harvested from a $25-\mathrm{cm}^{2}$ flask were suspended in $100 \mu \mathrm{l}$ of phosphate-buffered saline (PBS) and disrupted using an ultrasonic disrupter (TOMY SEIKO Co. Ltd., Tokyo, Japan) for 30 seconds under a strength of 8. A total of $5 \mu \mathrm{l}$ of the solution was then used for the analysis of total proteins, while the rest was used for the analysis of the ALP activity. The concentration of total proteins was determined using a Protein Assay Kit (Bio-Rad Laboratories, Inc., Tokyo, Japan), and the activity levels were expressed as unit/ $\mu \mathrm{g}$-total protein.

Calcified nodules produced by osteoblasts were stained according to the following procedure with a Calcified Nodule Staining Kit (Primary Cell Co., Ltd., Hokkaido, Japan): Cells cultured in 24-well plates were washed three times with PBS. Methanol cooled to $-20^{\circ} \mathrm{C}(500 \mu \mathrm{L})$ was subsequently added to each well, and the cells were incubated for 20 minutes at $4^{\circ} \mathrm{C}$ and then washed three times with $1 \mathrm{~mL}$ of water. Calcified nodules were stained using the substrate for staining $(400 \mu \mathrm{L})$, which contained alizarin red $\mathrm{S}$. The substrate was added to each well, and the cells were incubated for 10 minutes, after which the wells were washed three times with $1 \mathrm{~mL}$ of the wash buffer. The number of calcified nodules stained red by combining calcium and Alizarin red $\mathrm{S}$ was observed using a microscope.

\subsection{Gene Expression}

The total mRNA in the cells was purified, and cDNA was synthesized using an RNeasy Lipid Tissue Mini kit and QuantiTect Reverse Transcription Kit. The gene expression was determined using the real-time PCR method. The reaction mixture used for real-time PCR was prepared with a Rotor-Gene SYBR Green PCR Kit. Primers for $\beta$-actin, ESR2 (estrogen receptor 2), BMP2 (bone morphogenetic protein 2), RunX2 (Runt-related transcription factor 2), SP7, SP3, ATF4 (activating transcription factor 4), SOX5 and SOX9 were used for the QuantiTect Primer Assays. The three kits and primers were obtained from Qiagen K. K. (Tokyo, Japan). Real-time PCR was performed using the Rotor-GeneTM device (Qiagen K. K.). The reactions were performed for 80 cycles of treatment at $95^{\circ} \mathrm{C}$ for five seconds and $65^{\circ} \mathrm{C}$ for 30 seconds. The threshold line, Ct values and $\Delta \Delta \mathrm{Ct}$ values were determined using $\beta$-actin as the housekeeping gene (standard gene).

\section{Results}

\subsection{Suitable Culture Conditions for Differentiation to Osteoblasts}

We determined the culture conditions for differentiation to osteoblasts using MC3T3-E1 POBs. First, the ALP activity was examined, as the ALP activity is generally used as an indicator to estimate the primary stage of osteoblasts [25]. Based on the results of the preliminary tests, we selected the basic medium and culture time as DMEM containing hydrocortisone and glycerophosphate (OIM) and 10 days because the change in the ALP activity was most clearly observed under these conditions. MC3T3-E1 POBs cultured under these conditions were named "OB/POBs". The line for MC3T3-E1 in Figure 1 shows photographs of the stained cells, in which cells showing the ALP activity were stained dark blue using the TRACP\&ALP double-stain kit. The OB/POBs exhibited a high ALP activity (lane B), whereas the POBs (cultured in DMEM for 10 days) displayed a very low ALP activity (lane A). The line for MC3T3-E1 in Figure 2 shows microscopic photographs of the POBs and OB/POBs. The shape of the stained cells among OB/POBs (lane B) changed to the typical shape of osteoblasts (star-like shape). These results suggest that hydrocortisone and glycerophosphate are effective in promoting the differentiation of POBs to the preliminary stage of osteoblasts. 


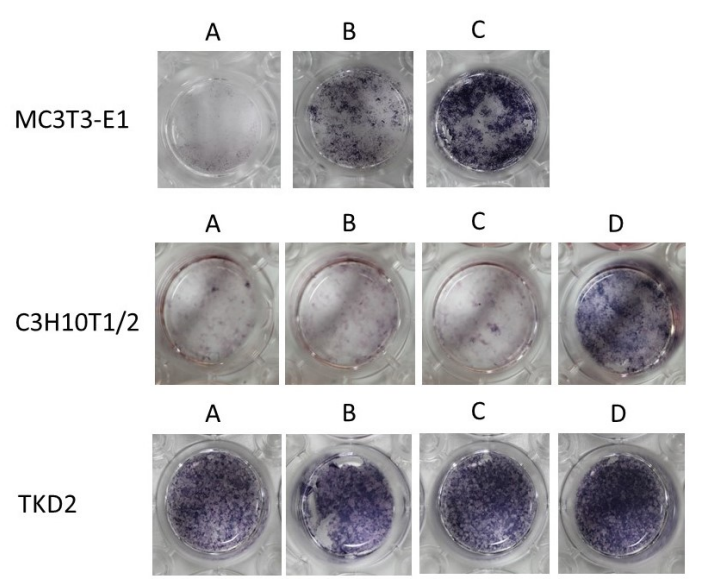

Figure 1. Photographs of the cells showing the ALP activity. The MC3T3-E1 POBs, C3H10T1/2 MSCs and TKD2 VECs cell lines are shown. The MC3T3-E1 POBs, C3H10T1/2 MSCs and TKD2 VECs were cultured in DMEM (lane A), OIM (lane B), OIM containing $10 \mu \mathrm{M}$ of ascorbic acid (lane C) and OIM containing $10 \mu \mathrm{M}$ of retinol (lane D). Cells exhibiting the ALP activity were stained dark blue for two hours using the TRACP \& ALP double-stain kit.
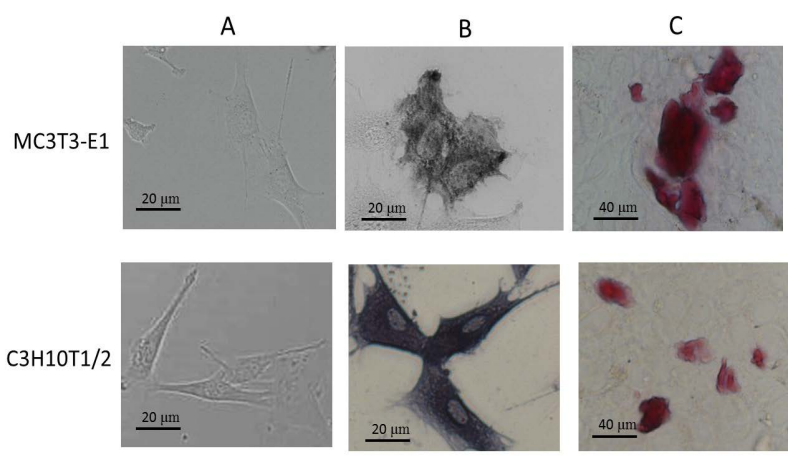

Figure 2. Shapes of the differentiated cells and calcified nodules. The MC3T3-E1 POBs and C3H10T1/2 MSCs cell lines are shown. Lane A: Original cells for MC3T3-E1 POBs and C3H10T1/2 MSCs. Lane B: Differentiated cells (OB/POBs and OB/MSCs). Lane C: Calcified nodules produced by the $\mathrm{OB} /$ $\mathrm{POBs}$ and $\mathrm{OB} / \mathrm{MSCs}$.

Next, the gene expression in the POBs and OB/POBs was examined using the real-time PCR method. The following 10 genes were used for the examination: four genes (ESR2, BMP2, RunX2 and SP7) expressed in the preliminary stage of osteoblasts, four genes (MSX2, DLX5, SP3 and ATFL4) expressed in the advanced stage of osteoblasts and two genes (SOX5 and SOX9) expressed in cartilage and osteoblasts [26]-[31]. C3H10T1/2 MSCs cultured in DMEM were used as standard cells, as POBs were differentiated from MSCs. Figure 3(A) shows the ratios of the expression levels observed in the POBs to those observed in the standard cells. The average expression levels in the BMP2, RunX2, SP7, MSX2, SOX5 and SOX9 genes in the MC3T3-E1 POBs were approximately 43,000, 3.7, 66, 24, 75 and 5.4 times higher than those observed in the standard cells, respectively. The ESR2 gene was also expressed at a low level, although it was not expressed in the C3H10T1/2 MSCs (data not shown in Figure 3 because the correct ratio could not be determined). Meanwhile, the expression levels of the DLX5 and SP3 genes were almost the same, while that of the ATFL4 gene was slightly decreased, respectively. Figure 3(B) shows the ratios of the expression levels in the OB/POBs to those observed in the POBs cells. The expression levels observed in the OB/POBs were similar or slightly lower than those ob- 

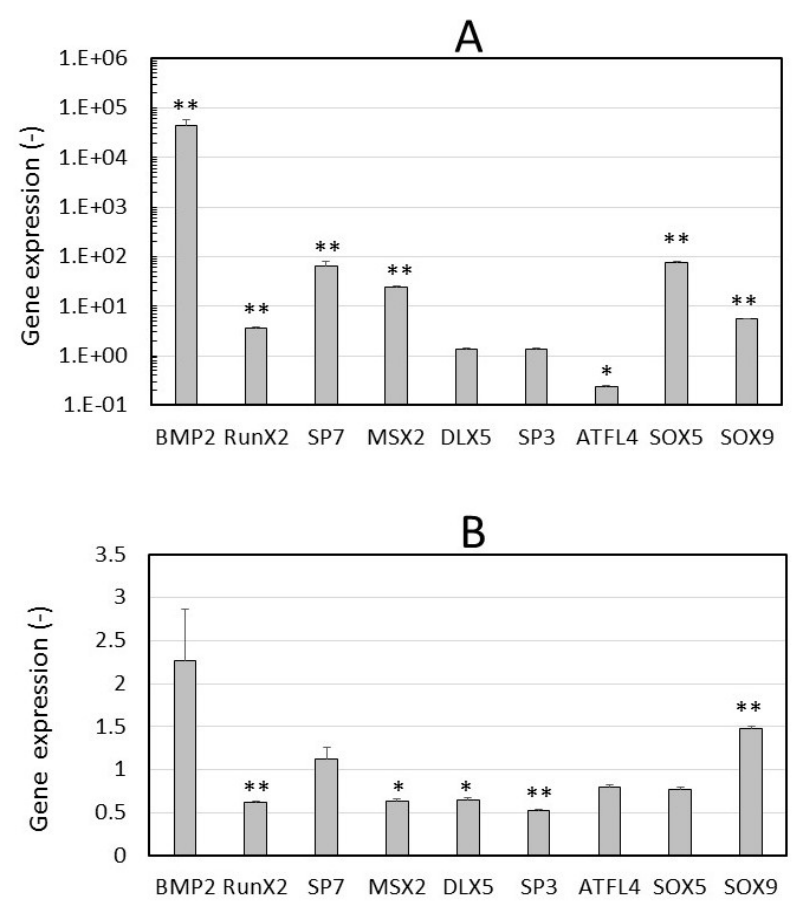

Figure 3. Gene expression levels in the MC3T3-E1 POBs and OB/POBs. (A) Ratios of the mRNA levels of the marker genes for osteoblasts in the MC3T3-E1 POBs to those observed in the C3H10T1/2 MSCs; (B) Ratios of the mRNA levels of the marker genes for osteoblasts in the OB/POBs to those observed in the POBs. Bars: mean \pm SD. ${ }^{* *} \mathrm{P}<0.01$ vs. control and ${ }^{*} \mathrm{P}<0.05$ (n $=3)$.

served in the POBs, whereas the ALP activity was significantly increased by the differentiation of the OB/POBs to POBs. These results suggest that the genetic characteristic of POBs are similar to those observed in the preliminary stage of osteoblasts and that the induction of the ALP activity occurs independently of the expression of the above genes.

Moreover, the conditions required to change the cells to the advanced stage were examined using OB/POBs. Calcified nodules stained red with Alizarin Red S using the Calcified Nodule Staining Kit were employed as an indicator of the advanced stage. When the OB/POBs were cultured in OIM, the cells were unable to produce calcified nodules (data not shown). These results suggest that some nutrients were inadequate to produce calcified nodules. Therefore, BCM (COSMO BIO INC.), instead of OIM, was used to induce the cells to the advantage stage. Figure 2 shows microscopic photographs of the calcified nodules obtained when the OB/POBs were cultured in BCM for 10 days. Calcified nodules (red staining), as shown in lane $\mathrm{C}$ along the line for MC3T3-E1, were observed in some places in the wells.

As the culture conditions for differentiation and the characteristics of the osteoblasts were successfully confirmed, we used these conditions and cells as positive controls for the next examination to estimate the degree of differentiation of MSCs and VECS to osteoblasts.

\subsection{Characteristics of the Differentiation of MSCs}

One of the candidate cells inducing osteoblasts in the vasculature is MSCs. Therefore, we examined the characteristics of the process of the differentiation of MSCs by applying the differentiation conditions obtained in Section 3.1. C3H10T1/2 MSCs were cultured in OIM for 15 days, and the proportion of cells showing the ALP activity was calculated every three days. The dyeing time was prolonged from two to 12 hours in this test because the ALP activity was much lower than that observed in the OB/POBs and a long reaction time (12 hours) was required to clearly distinguish between the stained and unstained cells. Figure 4 shows the ratio of the number 


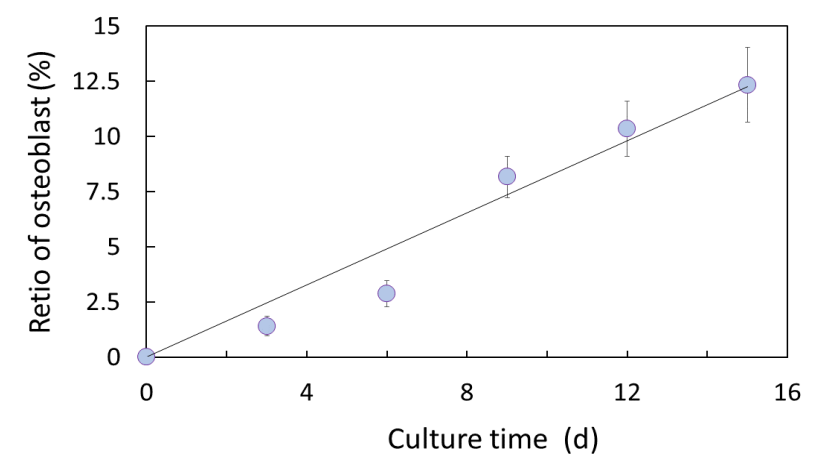

Figure 4. Effects of the culture time on the differentiation of C3H10T1/2 MSCs to the primary stage of osteoblasts. Ratios of osteoblasts: percentage of cells stained dark blue per the total number of cells $(n=4)$.

of stained cells to the total number of cells. This ratio increased in proportion to the culture time, and $12.5 \%$ of the cells exhibited the ALP activity at a low level by 15 days of culture.

In this experiment, the culture time was determined to be 15 days. The line for C3H10T1/2 in Figure 1 shows photographs of the stained cells showing the ALP activity when C3H10T1/2 MSCs were cultured in DMEM or OIM for 15 days. The cells cultured in OIM were named "OB/MSCs". The C3H10T1/2 MSCs did not display the ALP activity (lane A), whereas the OB/MSCs did (lane B). However, the activity levels were much lower than those observed in the OB/POBs. The line for C3H10T1/2 in Figure 2 shows optical microscopic photographs of the C3H10T1/2 MSCs and OB/MSCs. The shape of the stained cells among the OB/MSCs changed from a normal shape (line A) to the typical shape of osteoblasts (line B).

Moreover, we examined whether the OB/MSCs were able to produce calcified nodules. The line for C3H10T1/2 in Figure 2 shows microscopic photographs of the OB/MSCs cultured in BCM for 10 days stained using the Calcified Nodule Staining Kit. Calcified nodules were observed in the wells of the OB/MSC cultures (lane C), but not the C3H10T1/2 MSC cultures. However, the number of calcium nodules was limited and the size of the cells was smaller than that observed in the OB/POBs. Next, the genetic characteristics of the OB/MSCs were examined. Six genes (ESR2, BMP2, RunX2, SP7, SOX5 and SOX9) expressed at a high level in the POBs were selected, and the levels of mRNA in the C3H10T1/2 and OB/MSCs were determined. Figure 5(A) shows the ratios of the expression levels in the OB/MSCs to those observed in the standard cells (C3H10T1/2 MSCs). Consequently, the expression levels of the BMP2, SP7, SOX5 and SOX9 genes in the OB/MSCs cells were slightly lower than those observed in the C3H10T1/2 cells, whereas that of RunX2 was slightly higher (the level of ESR2 could not be determined correctly because the expression was too faint).

These results suggest that the effects of hydrocortisone and glycerophosphate on the differentiation of MSCs to osteoblasts are much lower than those observed in OB/POBs, although they weakly and slowly promote the differentiation of MSCs.

\subsection{Characteristics of the Differentiation of VECs}

We also applied the differentiation conditions to the differentiation of VECs to osteoblasts, as VECs are another candidate cell. TKD2 VECs were cultured in DMEM or OIM for 10 days; the latter cells were named "OB/VECs." The line for TKD2 in Figure 1 shows photographs of the stained cells exhibiting the ALP activity. Both the TKD2 VECs and OB/VECs displayed a high ALP activity without induction (line A), and the activity observed in the VECs was as high as that observed in the OB/POBs. The expression of the ALP activity in TKD2 VECs may therefore be similar to that seen under actual conditions in sites of plaque, as VECs often show the ALP activity following stimulation with inflammation.

Moreover, the production of calcified nodules by the OB/VECs was analyzed. Figure 6(A) and Figure 6(B) show microscopic photographs of the plates stained with the Calcified Nodule Staining Kit, in which VECs and OB/VECs were respectively cultured in BCM for 10 days. A large number of calcium nodules were observed in the wells of the OB/VECs (lane B), whereas few calcified nodules were detected in the wells of the TKD2 VECs (lane A). In addition, the genetic characteristics of the OB/VECs were examined. Figure 5(B) shows the ratios 

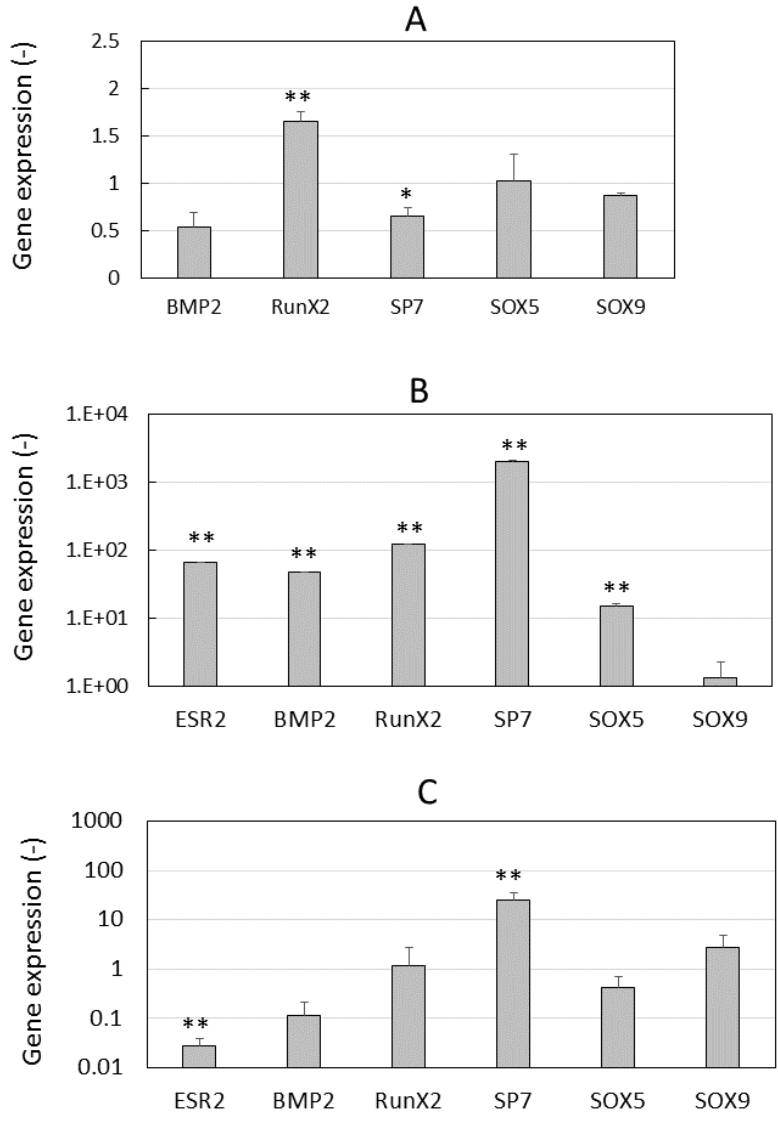

Figure 5. Effects of hydrocortisone, glycerophosphate and retinol on the differentiation of MSCs and VECs to osteoblasts. (A) Ratios of the mRNA levels in the OB/POBs to those observed in the C3H10T1/2 MCSs; (B) Ratios of the mRNA levels in the OB/VECs to those observed in the C3H10T1/2 MSCs; (C) Ratios of the mRNA levels in the OB-A/VECs to those observed in the OB/VECs. Bars: mean $\pm \mathrm{SD} .{ }^{* * *} \mathrm{P}<0.01$ vs. control and ${ }^{*} \mathrm{P}<0.05(\mathrm{n}=3)$.

A

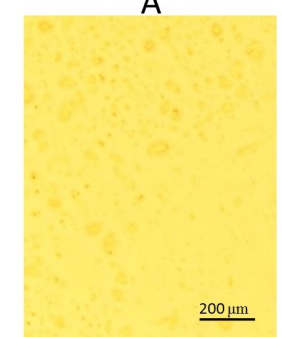

B

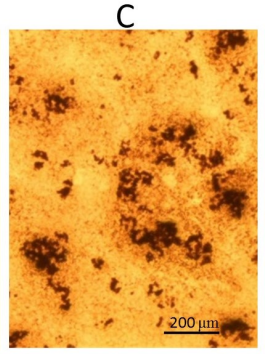

Figure 6. Effects of retinol on the production of calcified nodules. A, B and C: Calcified nodules produced by TKD2 VECs (lane A), OB/VECs (lane B) and OB-A/VECs (lane C). The three kinds of cells cultured in BCM for 10 days were stained using the Calcified Nodule Staining Kit.

of the expression levels in the OB/VECs to those observed in the standard cells (TKD2 VECs). The average expression levels of the ESR2, BMP2, RunX2, SP7, SOX5 and SOX9 genes in the OB/MSCs were 66, 47,124, 2,050 and 1.4 times higher than those observed in the standard cells. 
These results suggest that hydrocortisone and glycerophosphate strongly promote the differentiation of VECs to osteoblasts.

\subsection{Effects of Retinol and Ascorbic Acid on Differentiation}

Finally, we searched for other compounds strongly promoting the differentiation of VECs. In the preliminary examination, C3H10T1/2 MSCs were cultured in OIM containing vitamins or compounds related to fat for 15 days, and the ALP activity was examined. Six vitamins (vitamins A, B6, C, D3, E and K) and three compounds (insulin, fatty acids and cholesterol) related to fat were used for screening, as vitamins are important factors required for the formation of bones [18] [19] and obese subjects exhibit vascular calcification at high rates [4] [5]. C3H10T1/2 MSCs were used for the screening test because the ALP activity was already found to be expressed in TKD2 VECs. Consequently, retinol and ascorbic acid enhanced the ALP activity, whereas the other compounds did not show any promoting effect (data not shown). Therefore, further examinations were performed focusing on ascorbic acid and retinol.

The effects of ascorbic acid were first examined. MC3T3-E1 POBs, C3H10T1/2 MSCs and TKD2 VECs were cultured in OIM containing $10 \mu \mathrm{M}$ of ascorbic acid for 10 or 15 days, and the cultured cells were respectively named "OB-C/POBs", "OB-C/MSCs" and "OB-C/VECs". As shown in Figure 1, ascorbic acid demonstrated a promoting effect in the POBs, as the color of staining in the OB-C/POBs (lane C) was much deeper than that observed in the OB/POBs (lane B). However, the color of the ALP activity in the OB-C/MSCs and OB-C/VECs was only slightly deeper (or almost the same) than that observed in the control strains (C3H10T1/2 and TKD2). Figure 7 shows the ALP activity determined using the LaboAssayTMAP kit. The degree of increase in the ALP activity in the OB-C/MSCs was only 6\%. These results suggest that the promoting effects of ascorbic acid are weak in MSCs.

We next examined the effects of retinol on the C3H10T1/2 MSCs and TKD2 VECs. The cells were cultured in OIM containing $10 \mu \mathrm{M}$ of retinol for 15 or 10 days, and the cultured cells were named "OB-A/MSCs" and "OB-A/VECs", respectively. The lines for C3H10T1/2 and TKD2 in Figure 1 show the ALP activity in the OB-A/MSCs and OB-A/VECs. The color of the ALP activity in the OB-A/VECs (lane D) was almost the same as that observed in the OB/VECs (lane B), as the VECs showed a high activity. On the other hand, the ALP activity in the OB-A/MSCs was significantly increased in comparison (lane D); the activity was approximately nine times higher than that seen in the OB/MSCs, as shown in Figure 7. These results suggest that the promoting effects of retinol on differentiation were highest among the seven compounds.

Hence, the effects of retinol on the production of calcified nodules were examined using OB-A/MSCs and OB-A/VECs. Figure 6(C) shows the calcium nodules observed in the wells of the OB-A/VECs cultured in BCM for 10 days. The number of calcified nodules produced by the OB-A/VECs was remarkably increased compared to that produced by OB/VECs, and the size of the nodules was much larger. However, the amount of calcified nodules produced by the OB-A/MSCs was only slightly greater than that produced by the OB/MSCs (data not shown), as the efficiency of OIM in promoting the differentiation of MSCs was very low.

Finally, the effects of retinol on the gene expression were examined. Figure 5(C) shows the ratios of the gene expression levels in the OB-A/VECs to those observed in the OB/VECs. The expression levels in the OB-A/

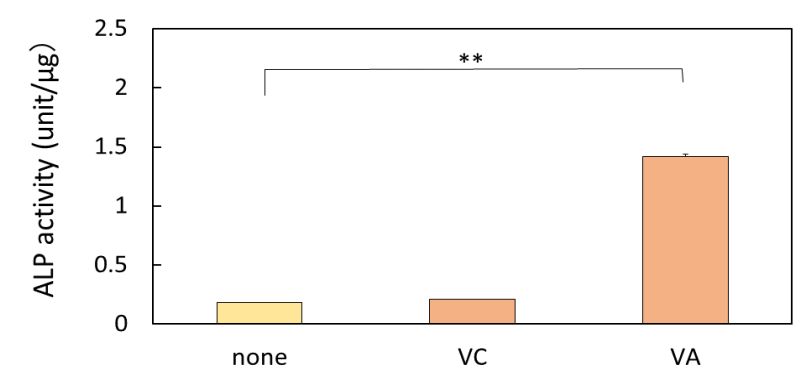

Figure 7. Effects of retinol and ascorbic acid on the ALP activity. C3H10T1/2 cells were cultured in OIM (none), OIM containing $10 \mu \mathrm{M}$ of ascorbic acid (VC) and OIM containing 10 $\mu \mathrm{M}$ of retinol (VA). Bars: mean $\pm \mathrm{SD}$. ${ }^{* *} \mathrm{P}<0.01$ vs. control (n $=4$ ). 
VECs were lower than those noted in the OB/VECs, and retinol did not have a positive effect on the gene expression.

\section{Discussion}

Vascular calcification at sites of arteriosclerosis often causes serious symptoms. Therefore, inhibiting this process is important for preventing serious symptoms. In this study, we sought to elucidate the characteristics of the process of differentiation of MSCs and VECs to osteoblasts in order to obtain important information regarding the onset of vascular calcification. Consequently, our results suggest the following novel ideas.

First, the culture conditions for differentiation to osteoblasts and characteristics of osteoblasts were determined using MC3T3-E1 POBs. OB/POBs, cells induced by culture in medium containing hydrocortisone and glycerophosphate, showed a high ALP activity, although the POBs alone did not exhibit these characteristics (Figure 1). These results suggest that hydrocortisone and glycerophosphate have a promoting effect on the differentiation of POBs to osteoblasts. The promoting effects of these two compounds have been previously documented in other studies using other types of POBs [20] [21], and our results support these findings. Moreover, we estimated the genetic characteristics of $\mathrm{POBs}$ and $\mathrm{OB} / \mathrm{POBs}$ because there were currently few genetic studies on MC3T3-E1 POBs. In this study, MC3T3-E1 POBs expressed the BMP2, RunX2, SP7, SOX5 and SoX9 genes (marker genes observed in the primary stage of osteoblast maturation) at high levels, and the levels of these genes were not enhanced by the differentiation of POBs to OB/POBs (Figure 3(A) and Figure 3(B)). These results suggest that the effect of hydrocortisone and glycerophosphate is to induce cells to differentiate to the primary stage of osteoblasts.

Next, we estimated the characteristics of MSCs and VECs with respect to their differentiation to osteoblasts by applying the conditions obtained with the POBs. Figure 1, Figure 2, Figure 4 and Figure 5 show the effects of hydrocortisone and glycerophosphate on the differentiation to C3H10T1/2 MSCs and TKD2 VECs. The efficiency of differentiation observed in the TKD2 VECs was much higher than that observed in the C3H10T1/2 MSCs. Moreover, the expression patterns of the genes in the OB/VECs were similar to those observed in the POBs, and the ESR2 and BMP2 genes, which were important for confirming the presence of osteoblasts [27] [30] [31], were highly expressed in the OB/VECs. Therefore, we speculate that hydrocortisone and glycerophosphate function as strong promoting compounds for the differentiation of VECs and that the appearance of osteoblasts in the vasculature may be primarily caused by VECs.

Finally, the effects of retinol on differentiation were examined. As shown in Figure 1, Figures 5-7, retinol exhibited a strong promoting effect on the differentiation of C3H10T1/2 MSCs and TKD2 VECs to osteoblasts. In particular, the effects on TKD2 VECs were strong, and large amounts of calcified nodules were produced by the OB-A/VECs, although retinol did not enhance the expression levels of the marker genes related to osteoblasts (Figure $5(C)$ ). These results suggest that retinol is a strong promoting compound of differentiation, although the function of retinol may not be to stimulate differentiation, but rather simply provide assistance to the process of differentiation. The current results for retinol provide important information regarding vascular calcification, as few report have demonstrated the promoting effects of retinol on the differentiation of VECs. Moreover, adequate cell lines and procedures to study the differentiation of VECs to osteoblasts have not been developed, and this area of research is thus lacking. The procedure used to differentiate MSCs and VECs in this study is useful for such research and is expected to become an important model. Indeed, we are now searching for effective inhibitors of differentiation to prevent vascular calcification using our procedure and will report the results in our next manuscript.

\section{Acknowledgements}

The authors sincerely thank Ms. Rumi Takeya, Satoko Tanaka, Ayako Higuchi, Minami Hosokawa, KumikoTashiro, Saori Mino, Ayumi Watanabe and Miwako Maeda for their assistance with the current research. This work was supported by a Grant-in-aid from the School of Human Sciences and the Research Institute at Kobe College.

\section{References}

[1] Jayalath, R.W., Mangan, S.H. and Golledge, J. (2005) Aortic Calcification. European Journal of Vascular and Endovascular Surgery: The Official Journal of the European. Society for Vascular Surgery, 30, 476-488. 
[2] Moe, S.M. and Chen, N.X. (2008) Mechanisms of Vascular Calcification in Chorinic Kidney Disease. Journal of the American Society of Nephrology, 19, 213-216. http://dx.doi.org/10.1681/ASN.2007080854

[3] Alagoz, S., Cebi, D., Akman, C., Altiparmak, M.R., Serdengecti, K. and Seyahi, N. (2014) Progression of Coronary Artery Calcification in Living Kidney Donors: A Follow-Up Study. Nephron Clinical Practice, 126, 144-150. http://dx.doi.org/10.1159/000362169

[4] Schurgin, S., Rich, S. and Mazzone, T. (2001) Increased Prevalence of Significant Coronary Artery Calcification in Patients with Diabetes. Diabetes Care, 24, 335-338. http://dx.doi.org/10.2337/diacare.24.2.335

[5] Meigs, J.B., Larson, M.G., D’Agostino, R.B., Levy, D., Clouse, M.E., Nathan, D.M., Wilson, P.W. and O’Donnell, C.J. (2002) Coronary Artery Calcification in Type 2 Diabetes and Insulin Resistance: The Framingham Offspring Study. Diabetes Care, 25, 1313-1319. http://dx.doi.org/10.2337/diacare.25.8.1313

[6] Dalen, J.E. and Devries, S. (2014) Diets to Prevent Coronary Heart Disease 1957-2013: What Have We Learned? The American Journal of Medicine, 127, 364-369. http://dx.doi.org/10.1016/j.amjmed.2013.12.014

[7] Lewis, B., Sullivan, D.R. and Watts, G.F. (2013) Thought for Food: Clinical Evidence for the Dietary Prevention Strategy in Cardiovascular Disease. International Journal of Evidence-Based Healthcare, 1, 330-336. http://dx.doi.org/10.1111/1744-1609.12047

[8] Bentzon, J.F., Otsuka, F., Virmani, R. and Falk, E. (2014) Mechanisms of Plaque Formation and Rupture. Circulation Research, 114, 1852-1866. http://dx.doi.org/10.1161/CIRCRESAHA.114.302721

[9] Shioi, A. (2010) Vascular Calcification and Remodeling in Diabets. The Journal of Japanese College of Angiology (Japanese), 50, 561-567.

[10] Shao, J.S., Cai, J. and Towler, D.A. (2006) Molecular Mechanisms of Vascular Calcification: Lessons Learned from the Aorta. Arteriosclerosis, Thrombosis, and Vascular Biology, 26, 1423-1430. http://dx.doi.org/10.1161/01.ATV.0000220441.42041.20

[11] Maurice, P., Blaise, S., Gayr, S., Debellem, L., Laffargue, M., Hornebeck, W. and Duca, L. (2013) Elastin Fragmentation and Atherosclerosis Progression: The Elastokine Concept. Trends in Cadiovascular Medicine, 23, 211-221. http://dx.doi.org/10.1016/j.tcm

[12] Sinha, A. and Vyavahare, N.R. (2013) High-Glucose Levels and Elastin Degradation Products Accelerate Osteogenesis in Vascular Smooth Muscle Cells. Diabetes \& Vascular Disease Research, 10, 410-419. http://dx.doi.org/10.1177/1479164113485101

[13] Atkinson, J. (2008) Age-Related Medial Elastocalcinosis in Arteries: Mechanisms, Animal Models, and Physiological Consequences. Journal of Applied Physiology, 105, 1643-1651. http://dx.doi.org/10.1152/japplphysiol.90476

[14] Luo, G., Ducy, P., McKee, M.D., Pinero, G.J., Loyer, E., Behringe, R.R. and Karsenty, G. (1997) Spontaneous Calcification of Arteries and Cartilage in Mice Lacking Matrix GLA Protein. Nature, 386, 78-81. http://dx.doi.org/10.1038/386078a0

[15] Tyson, K.L., Reynolds, J.L., McNair, R., Zhan, Q., Weissberg, P.L. and Shanahan, C.M. (2003) Osteo/Chondrocytic Transcription Factors and Their Target Genes Exhibit Distinct Patterns of Expression in Human Arterial Calcification. Arteriosclerosis Thrombosis and Vascular Biology, 23, 489-494. http://dx.doi.org/10.1161/01.ATV.0000059406.92165.31

[16] Satomi-Kobayashi, S., Kinugasa, M., Kobayashi, R., Hatakeyama, K., Kurogane, Y., Ishida, T., Emoto, N., Asada, Y., Takai, Y., Hirata, K. and Rikitake, Y. (2012) Osteoblast-Like Differentiation of Cultured Human Coronary Artery Smooth Muscle Cells by Bone Morphogenetic Protein Endothelial Cell Precursor-Derived Regulator (BMPER). Journal of Biological Chemistry, 287, 336-345. http://dx.doi.org/10.1074/jbc.M111.329110

[17] Speer, M.Y., Yang, H.Y., Brabb, T., Leaf, E., Look, A., Lin, W.L., Frutkin, A., Dichek, D. and Giachelli, C.M. (2009) Smooth Muscle Cells Give Rise to Osteochondrogenic Precursors and Chondrocytes in Calcifying Arteries. Circulation Research, 104, 733-741. http://dx.doi.org/10.1161/CIRCRESAHA.108.183053

[18] Choi, K.M., Seo, Y.K., Yoon, H.H., Song, K.Y., Kwon, S.Y., Lee, H.S. and Park, J.K. (2008) Effect of Ascorbic Acid on Bone Marrow-Derived Mesenchymal Stem Cell Proliferation and Differentiation. Journal of Bioscience and Bioengineering, 105, 586-594. http://dx.doi.org/10.1263/jbb.105.586

[19] Urban, K., Höhling, H.J., Lüttenberg, B., Szuwart, T. and Plate, U. (2012) An in Vitro Study of Osteoblast Vitality Influenced by the Vitamins C and E. Head \& Face Medicine, 8, 25. http://www.head-face-med.com/content/8/1/25

[20] Ireland, D.C., Bord, S., Beavan, S.R. and Compston, J.E. (2004) Hydrocortisone Increases the Rate of Differentiation of Cultured Human Osteoblasts. Journal of Cellular Biochemistry, 91, 594-601. http://dx.doi.org/10.1263/jbb.105.586

[21] Mikami, Y., Omoteyama, K., Kato, S. and Takagi, M. (2007) Inductive Effects of Dexamethasone on the Mineralization and the Osteoblastic Gene Expressions in Mature Osteoblast-Like ROS17/2.8 Cells. Biochemical and Biophysical Research Communications, 362, 368-373. http://dx.doi.org/10.1016/j.bbrc.2007.07.192

[22] Reznikoff, C.A., Brankow, D.W. and Heidelberger, C. (1973) Establishment and Characterization of a Cloned Line of 
C3H Mouse Embryo Cells Sensitive to Post-Confluence Inhibition of Division. Cancer Research, 33, 3231-3238.

[23] Sudo, H., Kodama, H.A., Amagai, Y., Yamamoto, S. and Kasai, S. (1983) In Vitro Differentiation and Calcification in a New Clonal Osteogenic Cell Line Derived from Newborn Mouse Calvaria. The Journal of Cell Biology, 96, 191-198.

[24] Yanai, N., Satoh, T., Kyo, S., Abe, K., Suzuki, M. and Obinata, M. (1991) A Tubule Cell Line Established from Transgenic Mice Harboring Temperature-Sensitive Simian Virus 40 Large T-Antigen Gene. Japanese Journal of Cancer Research, 82, 1344-1348. http://dx.doi.org/10.1111/j.1349-7006.1991.tb01803.x

[25] Pagani, F., Francucci, C.M. and Moro, L. (2005) Markers of Bone Turnover: Biochemical and Clinical Perspectives. Journal of Endocrinological Investigation, 28, 8-13.

[26] Matsubara, T., Kida, K., Yamaguchi, A., Hata, K., Ichida, F., Meguro, H., Aburatani, H., Nishimura, R. and Yoneda, T. (2008) BMP2 Regulates Osterix through Msx2 and Runx2 during Osteoblast Differentiation. Journal of Biological Chemistry, 28, 29119-29125. http://dx.doi.org/ 10.1074/jbc.M801774200

[27] Maureen, B., Joseph, D.L., Guoxin, N., Jinhua, W., Xing, L., Liangjun, Y., Ruidong, L., Wei, S., Hongyu, Z., Stephanie, H.K., Wenwen, Z., Jiye, Z., Yuhan, K., Sahitya, D., Mary, R.R., Abdullah, P., Rex, C.H., Hue, H.L., Jovito, A., Lewis, L.S. and Tong-Chuan, H. (2013) BMP Signaling in Mesenchymal Stem Cell Differentiation and Bone Formation. Journal of Biochemical Science and Engineering, 6, 32-52. http://dx.doi.org/10.4236/jbise.2013.68A1004

[28] Hong, S.H., Lu, X., Nanes, M.S. and Mitchell, J. (2009) Regulation of Osterix (Osx, Sp7) and the Osx Promoter by Parathyroid Hormone in Osteoblasts. Journal of Molecular Endocrinology, 43, 197-207. http://dx.doi.org/10.1677/JME-09-0012

[29] Choi, M.H., Noh, W.C., Park, J.W., Lee, J.M. and Suh, J.Y. (2011) Gene Expression Pattern during Osteogenic Differentiation of Human Periodontal Ligament Cells in Vitro. Journal of Periodontal \& Implant Science, 41, 167-175. http://dx.doi.org/10.1111/j.1525-1594.2007.00499.x

[30] Wiren, K.M., Chapman Evans, A. and Zhang, X.W. (2002) Osteoblast Differentiation Influences Androgen and Estrogen Receptor- $\alpha$ and $-\beta$ Expression. Journal of Endocrinology, 175, 683-694. http://dx.doi.org/10.1677/joe.0.1750683

[31] Okazaki, R., Inoue, D., Shibata, M., Saika, M., Kido, S., Ooka, H., Tomiyama, H., Sakamoto, Y. and Matsumoto, T. (2002) Estrogen Promotes Early Osteoblast Differentiation and Inhibits Adipocyte Differentiation in Mouse Bone Marrow Stromal Cell Lines That Express Estrogen Receptor (ER) $\alpha$ or $\beta$. Endocrinology, 143, 2349-2356. http://dx.doi.org/10.1210/en.143.6.2349 
Scientific Research Publishing (SCIRP) is one of the largest Open Access journal publishers. It is currently publishing more than 200 open access, online, peer-reviewed journals covering a wide range of academic disciplines. SCIRP serves the worldwide academic communities and contributes to the progress and application of science with its publication.

Other selected journals from SCIRP are listed as below. Submit your manuscript to us via either submit@scirp.org or Online Submission Portal.
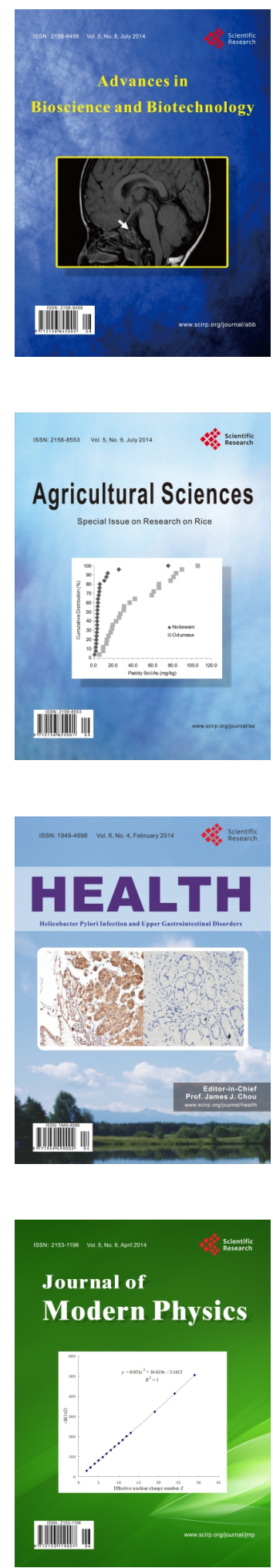
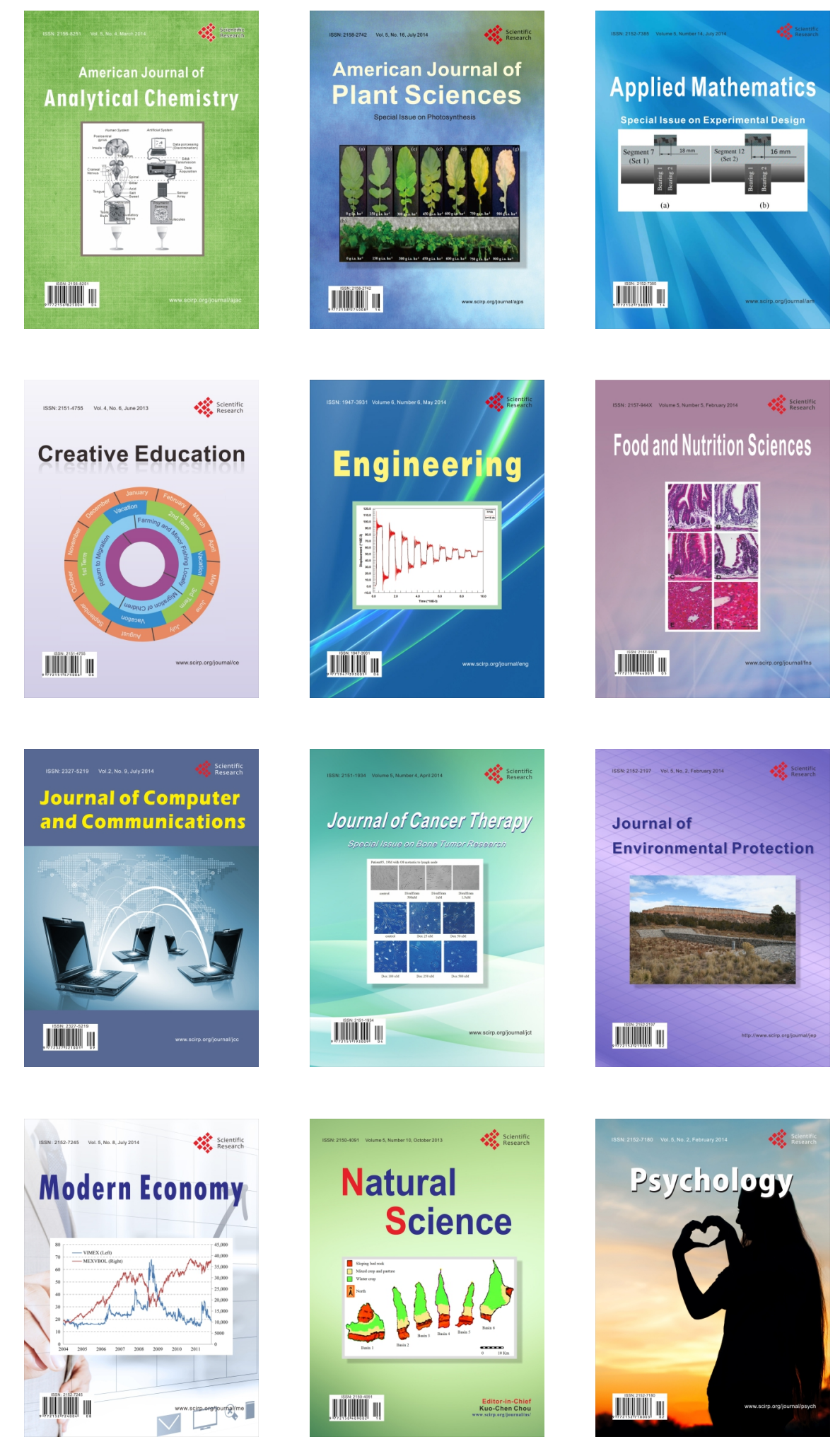